\title{
PENGEMBANGAN SISTEM PERHITUNGAN SHU (SISA HASIL USAHA) UNTUK MENINGKATKAN PENGHASILAN ANGGOTA PADA KOPERASI MANUNGGAL KARYA
}

\author{
Nurfitria Ningsih ${ }^{1)}$, Fatmawati Isnaini ${ }^{2)}$, Nurlia Handayani ${ }^{3)}$, Neneng $^{4)}$ \\ 1) Sistem Informasi, Universitas Sembilab Belas Nopember Kolaka \\ 2), 3), 4) Sistem Informasi Akuntansi, Universitas Teknokrat Indonesia \\ Jl. H.ZA Pagaralam, No 9-11, Labuhanratu,Bandarlampung \\ Email : ningsinurfitria@gmail.com ${ }^{l)}$,fatmawatisinaini@gmai;.com ${ }^{2)}$,nurliahandayani@gmail.com ${ }^{3)}$, \\ neneng@teknokrat.ac.id ${ }^{4)}$
}

\begin{abstract}
Abstrak
Pada suatu perusahaan khususnya Koperasi sangat diperlukan alat pengelolaan data secara cepat dan akurat terutama dalam pengelolaan Sisa Hasil Usaha (SHU). Sisa Hasil Usaha merupakan pendapatan koperasi yang diperoleh dalam satu tahun buku dikurangi dengan biaya, penyusutan, dan kewajiban lainnya termasuk pajak dalam tahun buku yang bersangkutan. Pada Koperasi Manunggal Karya kesulitan dalam perhitungan sisa hasil usaha dan penyimpanan data anggota dapat dikatakan masih kurang efisien dan efektif, karena belum menggunakan database, dan proses pencatatan masih menggunakan buku khusus untuk melakukan pencatatan sehingga sering terjadi kesalahan berupa kerangkapan dan kehilangan data dalam melakukan pencatatan data pada Koperasi Manunggal Karya. Salah satu bentuk penyelesaian dalam mencari solusi terkait permasalahan yang dihadapi oleh koperasi adalah dibuatkannya suatu aplikasi peminjaman dan perhitungan pada Koperasi Manunggal Karya. Sistem usulan ini mampu menghasilkan laporan sisa hasil usaha pada KSU Manunggal Karya. Pada tahap proses penginputan data dan perhitungan dapat dilakukan dengan lebih cepat, tepat, akurat dan efisien serta dapat disimpan dengan teratur, karena sudah ada sistem basis data (database) untuk menjaga keamanan dari data yang sudah dimasukkan.
\end{abstract}

Kata kunci: sistem, sisa hasil usaha, koperasi.

\section{Pendahuluan}

Pada umumnya saat ini perusahaan membutuhkan sistem informasi yang baik, karena perkembangan teknologi semakin pesat yang secara langsung berdampak pada semua perusahaan, baik itu yang sedang berkembang maupun yang sudah maju. Bagi sebuah organisasi, sistem informasi berfungsi sebagai alat bantu untuk pencapaian tujuan organisasi melalui penyedian informasi (Borman et al., 2012). Pada suatu perusahaan khususnya Koperasi sangat diperlukan alat pengelolaan data secara cepat dan akurat terutama dalam pengelolaan Sisa Hasil Usaha (SHU). Sisa Hasil Usaha merupakan pendapatan koperasi yang diperoleh dalam satu tahun buku dikurangi dengan biaya, penyusutan, dan kewajiban lainnya termasuk pajak dalam tahun buku yang bersangkutan (UU Koperasi No 25 Tahun 1992). Jika koperasi memperoleh pendapatan usaha yang banyak maka hal itu dapat mendorong peningkatan laba yang disebut juga dengan SHU (Sisa Hasil Usaha) (Andriani, 2017). Salah satu faktor yang mempenggaruhi Sisa Hasil Usaha adalah pemberian pinjaman yang diberikan oleh koperasi yang dapat memberikan manfaat bagi koperasinya sendiri dan anggotanya (Dewik \& Jember, 2016). Maka dari itu, Sisa Hasil Usaha (SHU) merupakan faktor penting yang menentukan kelangsungan berjalannya koperasi. Agar koperasi dapat berjalan dengan lancar, koperasi diharuskan memberikan pelayanan yang terbaik kepada anggota koperasi agar dapat melakukan transaksi simpan pinjam membeli barang, pembagian sisa hasil usaha dan lain - lain.

Koperasi Manunggal Karya adalah salah satu jenis koperasi yang ada diwilayah Jalan Sudirman, Kelurahan Dayamurni, Kecamatan Tumijajar, Kabupaten Tulang Bawang Barat. Pada Koperasi Manunggal Karya kesulitan dalam perhitungan sisa hasil usaha dan penyimpanan data anggota dapat dikatakan masih kurang efisien dan efektif, karena belum menggunakan database, dan proses pencatatan masih menggunakan buku khusus untuk melakukan pencatatan sehingga sering terjadi kesalahan berupa kerangkapan dan kehilangan data dalam melakukan pencatatan data pada Koperasi Manunggal Karya. Selain itu seringnya terjadi kesulitan dalam mencari berkas data dan seringnya terjadi tindak manipulasi data pada proses pembuatan laporan, karena pada sistem yang berjalan saat ini semua proses masih mengandalkan pencatatan pada buku agenda harian yang harus di isi secara manual, hal ini jugalah yang mengakibatkan lambatnya proses pembuatan laporan pada Koperasi Manunggal Karya.

Salah satu bentuk penyelesaian dalam mencari solusi terkait permasalahan yang dihadapi oleh koperasi adalah dibuatkannya suatu aplikasi peminjaman dan perhitungan pada Koperasi Manunggal Karya untuk dapat mengendalikan terjadinya kesalahan dalam pengolahan data yang ada pada koperasi dan mampu meningkatkan kualitas infomasi berdasarkan pengolahan 
data pinjaman yang menjadi pokok permasalahan yang ada pada koperasi saat ini.

\section{Pembahasan}

\subsection{Analisis Sisa Hasil Usaha (SHU)}

Dalam koperasi pendapatan yang diperoleh dalam satu tahun dikurangi penyusutan dan beban-beban dari tahun buku yang bersangkutan disebut sisa hasil usaha (SHU) (Soemarso, 2006). SHU merupakan keuntungan atau laba bagi koperasi setelah melalui proses penguranganpengurangan biaya yang dikeluarkan dari kegiatan usaha pada koperasi (Raidayani et al., 2017). Sisa hasil usaha setelah dikurangi untuk dana cadangan dibagikan kepada anggota sebanding dengan jasa yang dilakukan oleh masing-masing anggota. Pembagian sisa hasil usaha, bila diikhtisarkan adalah sebagai berikut :

a. Cadangan

b. SHU Bagian Anggota

c. Dana-dana Pengurus

d. Dana-dana Pendidikan

e. Dana Sosial

Anggaran dasar koperasi menetapkan bahwa pembagian sisa hasil usaha disajikan padat Tabel 1 berikut ini.

Tabel 1. Pembagian SHU Tahunan Untuk Anggota

\begin{tabular}{|l|c|}
\hline \multicolumn{1}{|c|}{ Nama } & Persentase \\
\hline Cadangan & $40 \%$ \\
\hline SHU Bagian Anggota & $30 \%$ \\
\hline Dana-Dana Pengurus & $20 \%$ \\
\hline Dana-Dana Pendidikan & $5 \%$ \\
\hline Dana Sosial & $5 \%$ \\
\hline
\end{tabular}

Contoh perhitungan sisa hasil usaha per anggota adalah sebagai berikut :

Andi dan Risky masing-masing memiliki simpanan sebesar Rp.10.700.000 dan Rp.15.300.000 dan keduanya memperoleh pendapatan masing-masing sebesar Rp.800.000. :

SHU per anggota $=$ Total Simpanan Anggota $\times$ Pendapatan

Jumlah Seluruh Simpanan Anggota

SHU Andi $=\frac{\text { Rp. } 10.700 .000}{\text { Rp.26.000.000 }} \times$ Rp. $800.000=329.230$

SHU Risky $=\frac{\text { Rp. } 15.300 .000}{R p .26 .000 .000} \times R p .800 .000=470.769$ Rp.26.000.000

\subsection{Analisis Masalah}

Untuk mengetahui permasalahan yang ada ,maka yang pertama kali dilakukan adalah mengetahui prosedur system yang berjalan. Prosedur sistem yang berjalan pada saat ini sebagai berikut :

1. Petugas mencatat daftar perkiraan yang ada di KSU Manunggal Karya.

2. Petugas mencatat setiap transaksi perkiraan penerimaan dan pengeluaran yang terjadi di KSU Manunggal Karya.

3. Petugas mengklasifikasi perkiraan sesuai kelompok perkiraan.

4. Petugas mencatat kedalam buku perkiraan untuk setiap transaksi yang terjadi.

5. Laporan yang telah dibuat oleh petugas diserahkan kepada pimpinan.

Permasalahan pokok pada Koperasi Manunggal Karya adalah sistem kerja yang masih manual. Sistem yang masih manual tersebut bisa membawa dampak yangn egatif bagi keseluruhan sistem manajemen koperasi. Aktivitas kerja dikoperasi menjadi lambat dikarenakan dalam proses pencatatan, perhitungan,pembukuan dan pengecekan data masih secara manual, sehingga sering terjadi kesalahan dalam pencatatan, perhitungan, pembukuan dan pengecekan data.

\subsection{Deain Sistem}

Desain sistem bertujuan untuk memberikan gambaran apa yang seharusnya dikerjakan dan bagaimana tampilannya (Damayanti \& Sulistiani, 2017). Penelitian ini menggunakan desain system UML (unified Modelling Language). UML adalah Bahasa visual untuk pemodelan dan komunikasi mengenai sebuah sistem dengan menggunakan diagram dan teks-teks pendukung (Pressman, 2012). Diagram UML yang digunakan pada penelitian ini adalah Use Case Diagram. Use Case Diagram merupakan rancangan yang mendeskripsikan apa yang akan dilakukan oleh system (Rulyana \& Borman, 2014). Terdapat dua aktor yang menjalankan sistem yaitu admin dan pimpinan. Use Case Diagram sistem perhitungan SHU dapat dilihat pada gambar 1bawah ini:

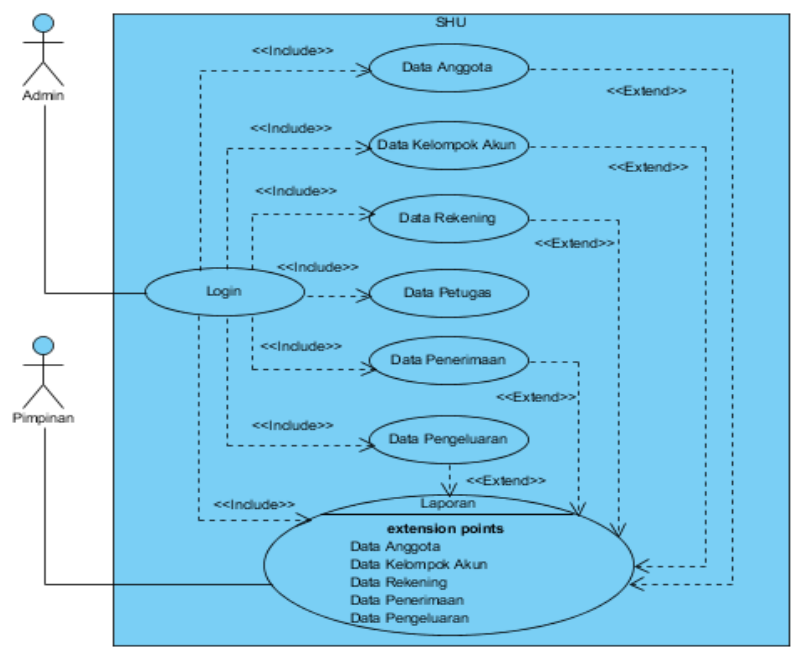

Gambar 1. Use Case Diagram Sistem Perhitungan SHU 


\subsection{Implementasi Sistem}

Sistem yang dibangun diharapkan mempermudah peminjaman dan perhitungan pada Koperasi Manunggal Karya untuk dapat mengendalikan terjadinya kesalahan dalam pengolahan data yang ada pada koperasi dan mampu meningkatkan kualitas infomasi berdasarkan pengolahan data pinjaman.

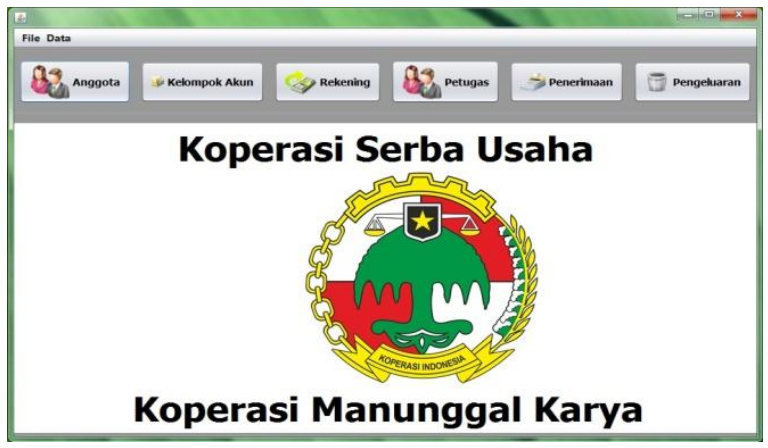

Gambar 1. Menu Utama Sistem Perhitungan SHU

Pada sistem perhitungan SHU terdapat beberapa fitur diantaranya fitur pengelolaan data anggota Koperasi, data kelompok, data rekening, data petugas, data penerimaan dan data pengeluaran. Pada Data penerimaan admin dapat menginputkan hasil penerimaan yang diterima dari setiap anggota maupun organisasi (Gambar 2).

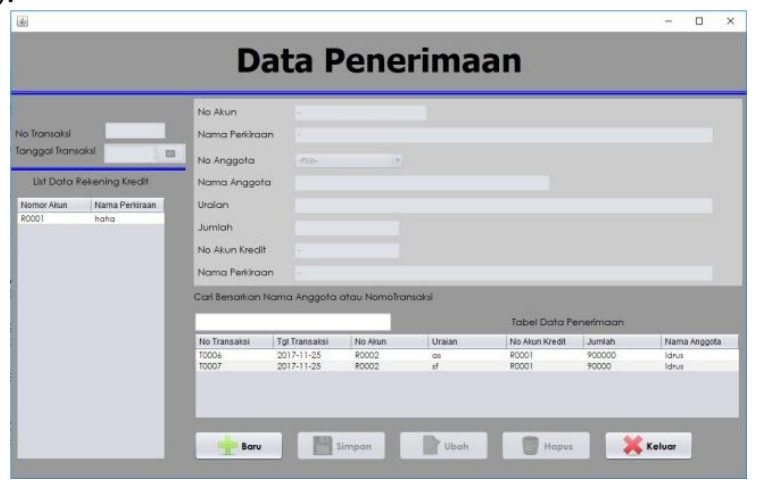

Gambar 2. Form Data Penerimaan Sistem Perhitungan SHU

Untuk menginputkan seberapa banyak pengeluaran yang terjadi dapat dikelola melalui form pengeluaran (Gambar $3)$.

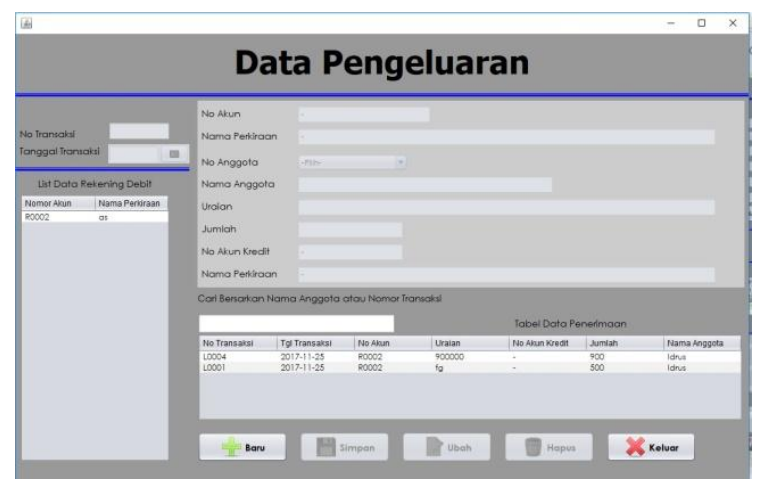

Gambar 3. Form Data Pengeluaran Sistem Perhitungan SHU

Report atau laporan yang dihasilkan oleh system ini antara lain laporan daftar akun perkiraan, laporan pendapatan dan laporan Sisa Hasil Usaha (SHU).

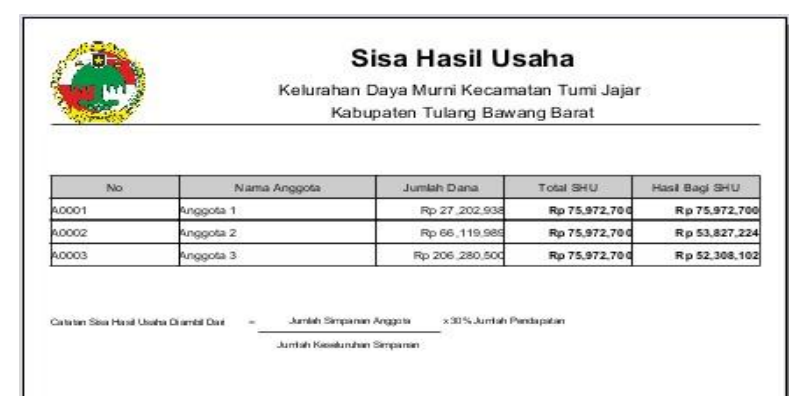

Gambar 6. Laporan Sisa Hasil Usaha (SHU)

\subsection{Pengujian Sistem}

Pada tahap ini menjelaskan mengenai bagaimana hasil evaluasi sistem yang dilakukan. Penilaian terhadap aplikasi bukan terletak pada spesifikasi logika fungsi aplikasi tersebut, namun pada input dan output. Dengan berbagai input yang diberikan akan dievaluasi apakah suatu sistem dapat memberikan output yang sesuai dengan harapan penguji. Salah satu konsep pengujian sistem adalah debugging, debugging terjadi sebagai akibat dari pengujian yang berhasil. Jika test case mengungkap kesalahan, maka debugging adalah proses yang menghasilkan penghilangan kesalahan. Setelah dilakukan pengujian debugging system perhitungan SHU berjalan dengan baik dan tidak terdapat kesalahan

\section{Kesimpulan}

Setelah menyelesaikan perancangan Sistem Informasi Akuntansi Perhitungan Sisa Hasil Usaha pada KSU Manunggal Karya penulis menarik beberapa kesimpulan sebagai berikut:

1. Sistem usulan ini mampu menghasilkan laporan sisa hasil usaha pada KSU Manunggal Karya.

2. Pada tahap proses penginputan data dan perhitungan dapat dilakukan dengan lebih cepat, tepat, akurat dan efisien serta dapat disimpan dengan teratur, karena sudah ada sistem basis data (database) untuk menjaga keamanan dari data yang sudah dimasukkan.

\section{Daftar Pustaka}

Andriani, 2017. Analisis Perkembangan Modal Dan Pendapatan Usaha Terhadap Sisa Hasil Usaha Pada Koperasi Tani (KOPTAN) Jasa Tirta Kab. Tulungagung. Simki-Economic, 1(4).

Borman, R.I., Rosidi, A. \& Arief, M.R., 2012. Evaluasi Penerapan Sistem Informasi Manajemen Kepegawaian (SIMPEG) Di Badan Kepegawaian Daerah Kabupaten Pamekasan Dengan Pendekatan 
Human-Organizationtechnology (HOT) Fit Model. Jurnal Teknologi Informasi, VII(20).

Damayanti \& Sulistiani, H., 2017. Sistem Informasi Pembayaran Biaya Sekolah Pada SD Ar-Raudah Bandar Lampung. Jurnal TEKNOINFO, 11(2).

Dewik, N.K.S. \& Jember, I.M., 2016. Faktor-Faktor Yang Mempengaruhi Sisa Hasil Usaha (Shu) Koperasi Simpan Pinjam (Ksp) Di Kecamatan Kuta Utara Kabupaten Badung. JurnaliEPiUnud, $5(7)$.

Pressman, R.S., 2012. Rekayasa Perangkat Lunak. Yogyakarta.

Raidayani, Muhammad, S. \& Faisal, 2017. Faktor-Faktor Yang Mempengaruhi Sisa Hasil Usaha (SHU) Pada Koperasi Di Kabupaten Aceh Barat. JURNAL PERSPEKTIF EKONOMI DARUSSALAM, 3(2).

Rulyana, D. \& Borman, R.I., 2014. Aplikasi Simulasi Tes Potensi Akademik Berbasis Mobile Platform Android. In Seminar Nasional FMIPA-Universitas Terbuka. DKI Jakarta, 2014.

Soemarso, S.R., 2006. Akuntansi Suatu Pengantar. Jakarta: Salemba Empat. 